Acta Crystallographica Section E

Structure Reports

Online

ISSN 1600-5368

\section{Ethylenediammonium dichloride}

\section{Milad Gabro, Roger A. Lalancette* and Ivan Bernal}

Carl A. Olson Memorial Laboratories, Department of Chemistry, Rutgers University, Newark, NJ 07102, USA

Correspondence e-mail: rogerlal@andromeda.rutgers.edu

Received 7 May 2009; accepted 14 May 2009

Key indicators: single-crystal X-ray study; $T=100 \mathrm{~K}$; mean $\sigma(\mathrm{C}-\mathrm{C})=0.002 \AA$; $R$ factor $=0.028 ; w R$ factor $=0.070 ;$ data-to-parameter ratio $=11.8$.

The title ionic compound, $\mathrm{C}_{2} \mathrm{H}_{10} \mathrm{~N}_{2}{ }^{2+} \cdot 2 \mathrm{Cl}^{-}$, crystallizes with a center of symmetry within the cation. Each of the positively charged ammonium ends of the molecule is trigonally hydrogen bonded to three different chloride counter-ions, while each of the chloride ions is trigonally hydrogen bonded to three different ethylenediammonium cations. The hydrogen-bonding network leads to stabilization of the structure.

\section{Related literature}

For the applications of ethylenediamine, see: Kotti et al. (2006); Warner (1912).

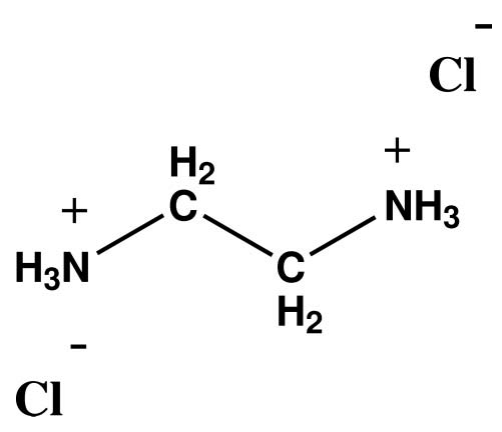

\section{Experimental}

Crystal data

$\mathrm{C}_{2} \mathrm{H}_{10} \mathrm{~N}_{2}{ }^{2+} \cdot 2 \mathrm{Cl}^{-}$

$M_{r}=133.02$

Monoclinic, $P 2_{1} / c$

$a=4.3807$ (3) $\AA$

$b=6.8569$ (4) $\AA$

$c=9.9464(5) \AA$

$\beta=91.192(2)^{\circ}$

$$
\begin{aligned}
& V=298.71(3) \AA^{3} \\
& Z=2 \\
& \text { Cu K } \alpha \text { radiation } \\
& \mu=8.71 \mathrm{~mm}^{-1} \\
& T=100 \mathrm{~K} \\
& 0.45 \times 0.30 \times 0.29 \mathrm{~mm}
\end{aligned}
$$

\section{Data collection}

Bruker SMART CCD APEXII area-detector diffractometer

Absorption correction: multi-scan (SADABS; Sheldrick, 2001)

$T_{\min }=0.085, T_{\max }=0.090$

1654 measured reflections 521 independent reflections 520 reflections with $I>2 \sigma(I)$ $R_{\text {int }}=0.022$

Refinement

$R\left[F^{2}>2 \sigma\left(F^{2}\right)\right]=0.028$

$w R\left(F^{2}\right)=0.070$

$S=1.15$

521 reflections

44 parameters

Only $\mathrm{H}$-atom coordinates refined

$\Delta \rho_{\max }=0.41{\mathrm{e} \AA^{-3}}^{-3}$

$\Delta \rho_{\min }=-0.31 \mathrm{e} \AA^{-3}$

Table 1

Hydrogen-bond geometry $\left(\AA{ }^{\circ}\right)$.

\begin{tabular}{lccll}
\hline$D-\mathrm{H} \cdots A$ & $D-\mathrm{H}$ & $\mathrm{H} \cdots A$ & $D \cdots A$ & $D-\mathrm{H} \cdots A$ \\
\hline $\mathrm{N} 1-\mathrm{H} 1 E \cdots \mathrm{Cl} 1$ & $0.89(2)$ & $2.27(2)$ & $3.1514(15)$ & $175(2)$ \\
$\mathrm{N} 1-\mathrm{H} 1 D \cdots \mathrm{Cl}{ }^{\mathrm{i}}$ & $0.80(3)$ & $2.39(3)$ & $3.1770(15)$ & $170(2)$ \\
$\mathrm{N} 1-\mathrm{H} 1 C \cdots \mathrm{Cl} 1^{\text {ii }}$ & $0.91(2)$ & $2.29(2)$ & $3.1922(15)$ & $171(2)$ \\
\hline Symmetry codes: (i) $-x+1, y+\frac{1}{2}-z+\frac{3}{2} \cdot\left(\right.$ ii) $x,-y+\frac{1}{2} z+\frac{1}{2}$ &
\end{tabular}

Data collection: $A P E X 2$ (Bruker, 2006); cell refinement: $A P E X 2$; data reduction: SAINT (Bruker, 2005); program(s) used to solve structure: SHELXTL (Sheldrick, 2008); program(s) used to refine structure: SHELXTL; molecular graphics: SHELXTL; software used to prepare material for publication: $S H E L X T L$.

The authors acknowledge support by the NSF-CRIF (grant No. 0443538).

Supplementary data and figures for this paper are available from the IUCr electronic archives (Reference: LH2823).

\section{References}

Bruker (2005). SAINT. Bruker AXS Inc., Madison, Wisconsin, USA. Bruker (2006). APEX2. Bruker AXS Inc., Madison, Wisconsin, USA.

Kotti, S. R. S. S., Timmons, C. \& Li, G. (2006). Chem. Biol. Drug Des. 67, 101114.

Sheldrick, G. M. (2001). SADABS. University of Göttingen, Germany.

Sheldrick, G. M. (2008). Acta Cryst. A64, 112-122.

Warner, A. (1912). Chem. Ber. 45, 121-130. 


\section{supporting information}

Acta Cryst. (2009). E65, o1352 [doi:10.1107/S1600536809018327]

\section{Ethylenediammonium dichloride}

\section{Milad Gabro, Roger A. Lalancette and Ivan Bernal}

\section{S1. Comment}

Ethylenediamine has been used for approximately one century in the preparation of many metal coordination complexes, such as tris(ethylenediamine)cobalt(III) chloride (Warner, 1912). This is an important precursor to many polymers, chelating agents and pharmaceuticals, including drug design (Kotti, et al., 2006). Since it is a widely used building block in the synthesis of many materials, its structure is of interest. However, it exists as a liquid at room temperature, with a melting point of $282 \mathrm{~K}$. We report herein the crystal structure of the dichloride salt of ethylenediamine.

Ethylenediammonium dichloride (I) crystallizes with a center of symmetry in the ethylene moiety. Fig. 1 shows the dication with one chloride counterion hydrogen bonded at each terminal nitrogen atom; however, there are three such chloride ions surrounding each $\mathrm{N}$ atom. The angles around both $\mathrm{N} 1$ and $\mathrm{C} 1$ are essentially tetrahedral, with the N1-C1 $-\mathrm{C} 1[1-x, 1 / 2+y, 2.5-z]$ angle $=109.68(18)^{\circ}$, and the angles around $\mathrm{N} 1$ range from 102 (2) to $115(2)^{\circ}$.

Fig. 2 illustrates the packing of (I). Each of the chloride counterions is trigonally $\mathrm{H}$ bonded to three different ethylenediammonium cations with $\mathrm{N} \cdots \mathrm{Cl}$ bond distances of 3.1516 (15), 3.1931 (16) \& 3.1749 (16) $\AA$ and angles $\mathrm{N}-\mathrm{H} \cdots \mathrm{Cl}$ of 175 (2), 170 (2) \& 173 (2) ${ }^{\circ}$ (see Table 1). Protonation occurs at both ammonium sites in the molecule (the 2 nd is centrosymmetrically related); as a result, each nitrogen is also trigonally $\mathrm{H}$ bonded to three symmetry-related chlorides. This $\mathrm{H}$ bonding fixes both the chloride anions and the organic dication very rigidly in the lattice. Therefore, through symmetry, there exist six $\mathrm{N}-\mathrm{H} \cdots \mathrm{Cl}$ bonds for each molecule, which leads to a great degree of stabilization in the structure.

\section{S2. Experimental}

Compound (I) was prepared by mixing $2.5 \mathrm{ml}$ of ethylenediamine with $62 \mathrm{ml}$ of water. Then $7.5 \mathrm{ml}$ of $12 \mathrm{M} \mathrm{HCl}$ were added and this mixture was stirred in an ice bath at $273 \mathrm{~K}$ until a white precipitate formed. The white precipitate was filtered and washed 3 times with methyl alcohol. The product was dissolved in water and then $12 \mathrm{M} \mathrm{HCl}$ was added until precipitation just began; a small quantity of water was then added to redissolve the precipitate. This mixture was allowed to evaporate slowly and large colorless needles of (I) formed, which were used directly for X-ray analyis.

\section{S3. Refinement}

All $\mathrm{H}$ atoms for (I) were found in electron density difference maps. The ammonium and methylene $\mathrm{Hs}^{\prime}$ fractional coordinates were allowed to refine, but their isotropic thermal parameters were set at $U_{\text {iso }}(\mathrm{H})=1.5 U_{\text {eq }}(\mathrm{N})$ and $1.2 U_{\text {eq }}(\mathrm{C})$. 


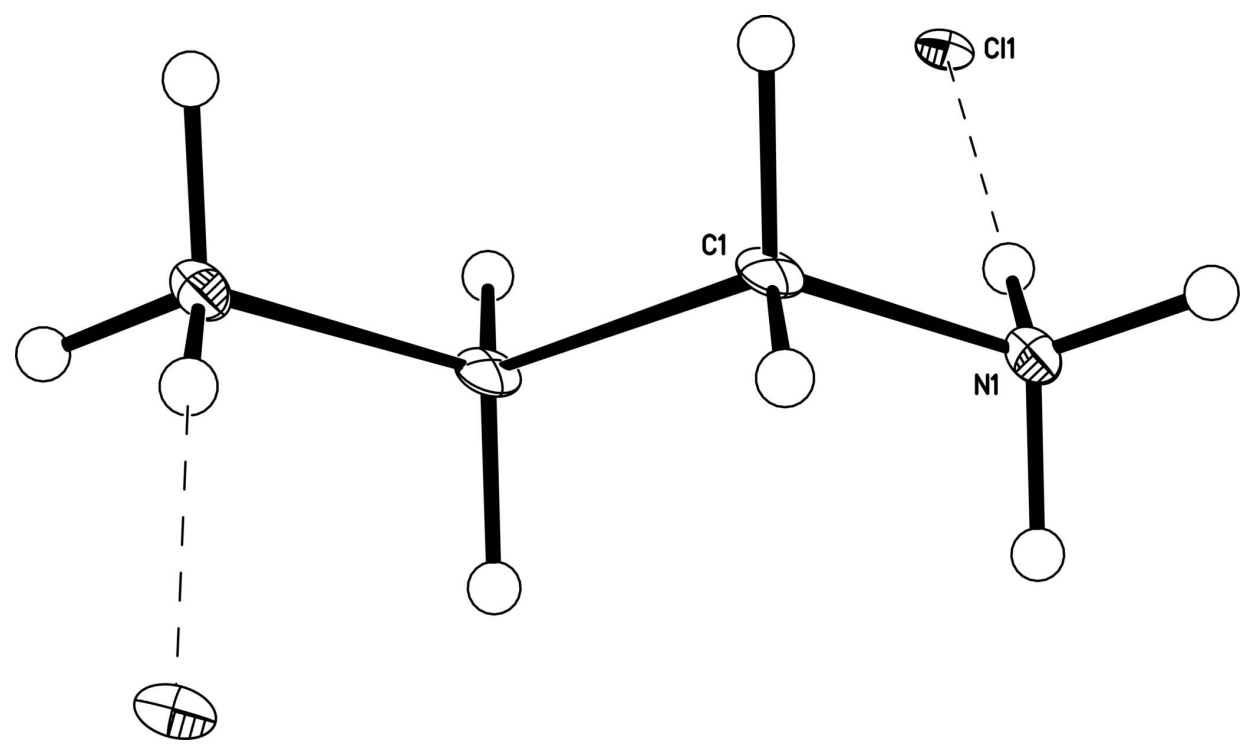

\section{Figure 1}

The molecluar structure of (I), with its numbering; one-half of the molecule is generated through a center of symmetry at $1 / 2,1 / 2,1 / 2$ in the chosen unit cell. The $\mathrm{H}$ bonds to the chlorides are shown as dashed lines. Displacement ellipsoids are drawn at the $80 \%$ probability level. 


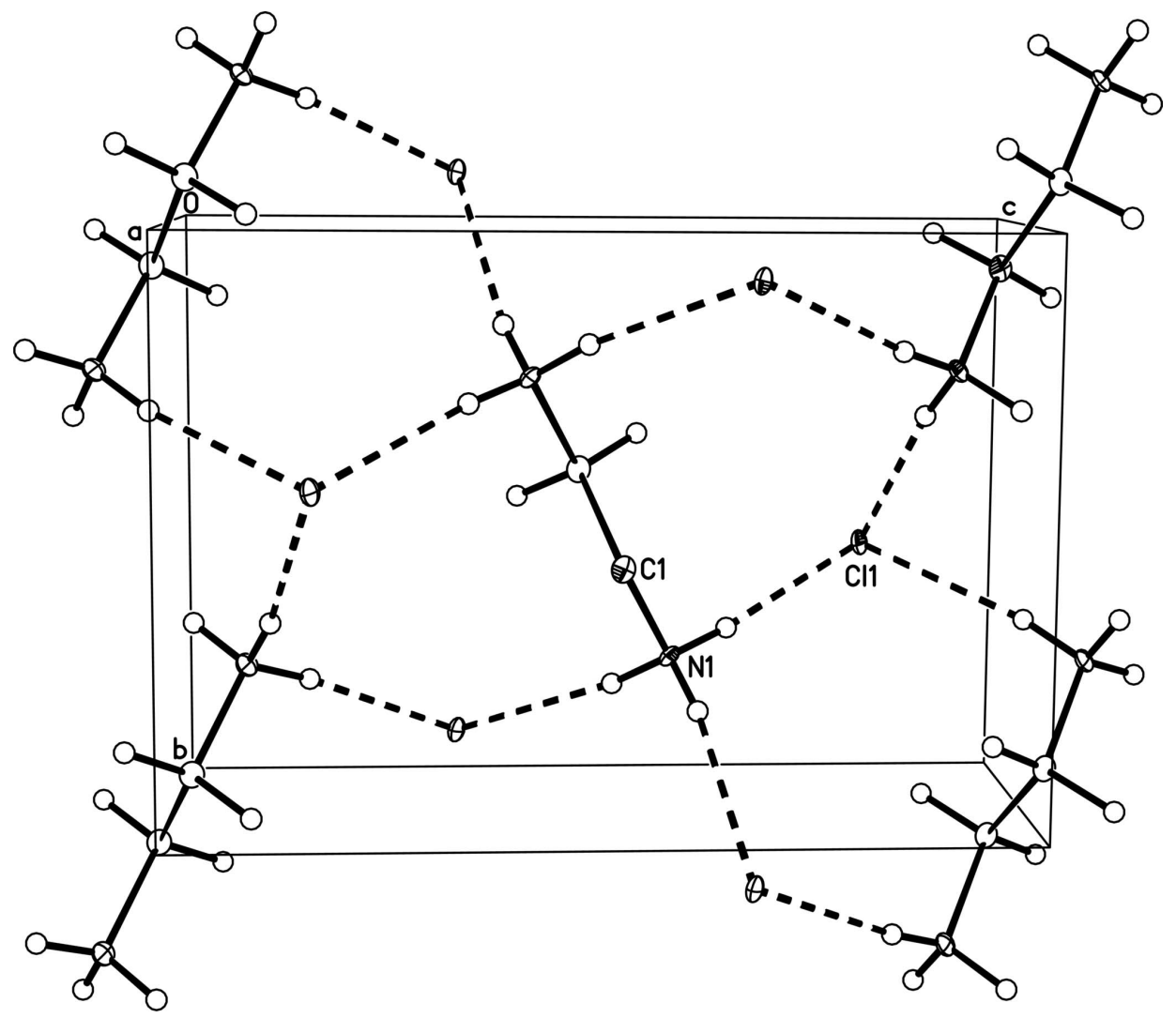

Figure 2

A partial packing diagram for (I), with extracellular molecules, illustrating the trigonal hydrogen bonding of the chloride ion to three different ethylenediammonium cations. Also the three $\mathrm{H}$ atoms of the ammonium are bound to three different chloride counterions. All of the cations lie on centers of symmetry, at 1/2,1/2,1/2 and 1/2,0,0. Displacement ellipsoids are drawn at the $80 \%$ probability level.

\section{Ethylenediammonium dichloride}

Crystal data

$\mathrm{C}_{2} \mathrm{H}_{10} \mathrm{~N}_{2}{ }^{2+} \cdot 2 \mathrm{Cl}^{-}$

$M_{r}=133.02$

Monoclinic, $P 2_{1} / c$

Hall symbol: -P $2 \mathrm{ybc}$

$a=4.3807$ (3) $\AA$

$b=6.8569(4) \AA$

$c=9.9464(5) \AA$

$\beta=91.192(2)^{\circ}$

$V=298.71(3) \AA^{3}$

$Z=2$

\section{Data collection}

Bruker SMART CCD APEXII area-detector diffractometer

Radiation source: fine-focus sealed tube

Graphite monochromator

$\varphi$ and $\omega$ scans
$F(000)=140$

$D_{\mathrm{x}}=1.479 \mathrm{Mg} \mathrm{m}^{-3}$

$\mathrm{Cu} K \alpha$ radiation, $\lambda=1.54178 \AA$

Cell parameters from 1684 reflections

$\theta=4.5-67.4^{\circ}$

$\mu=8.71 \mathrm{~mm}^{-1}$

$T=100 \mathrm{~K}$

Parallelepiped, colourless

$0.45 \times 0.30 \times 0.29 \mathrm{~mm}$

Absorption correction: multi-scan

(SADABS; Sheldrick, 2001)

$T_{\text {min }}=0.085, T_{\text {max }}=0.090$

1654 measured reflections

521 independent reflections 
520 reflections with $I>2 \sigma(I)$

$R_{\text {int }}=0.022$

$\theta_{\max }=67.8^{\circ}, \theta_{\min }=7.9^{\circ}$

\section{Refinement}

Refinement on $F^{2}$

Least-squares matrix: full

$R\left[F^{2}>2 \sigma\left(F^{2}\right)\right]=0.028$

$w R\left(F^{2}\right)=0.070$

$S=1.15$

521 reflections

44 parameters

0 restraints

Primary atom site location: structure-invariant direct methods

Secondary atom site location: difference Fourier map

Special details

Experimental. crystal mounted on cryoloop using Paratone-N

Geometry. All e.s.d.'s (except the e.s.d. in the dihedral angle between two 1.s. planes) are estimated using the full covariance matrix. The cell e.s.d.'s are taken into account individually in the estimation of e.s.d.'s in distances, angles and torsion angles; correlations between e.s.d.'s in cell parameters are only used when they are defined by crystal symmetry. An approximate (isotropic) treatment of cell e.s.d.'s is used for estimating e.s.d.'s involving 1.s. planes.

Refinement. Refinement of $F^{2}$ against ALL reflections. The weighted $R$-factor $w R$ and goodness of fit $S$ are based on $F^{2}$, conventional $R$-factors $R$ are based on $F$, with $F$ set to zero for negative $F^{2}$. The threshold expression of $F^{2}>\sigma\left(F^{2}\right)$ is used only for calculating $R$-factors(gt) $e t c$. and is not relevant to the choice of reflections for refinement. $R$-factors based on $F^{2}$ are statistically about twice as large as those based on $F$, and $R$ - factors based on ALL data will be even larger.

Fractional atomic coordinates and isotropic or equivalent isotropic displacement parameters $\left(\AA^{2}\right)$

\begin{tabular}{lllll}
\hline & $x$ & $y$ & $z$ & $U_{\text {iso }} / U_{\text {eq }}$ \\
\hline C11 & $0.91302(8)$ & $0.07997(5)$ & $0.67014(3)$ & $0.0043(3)$ \\
C1 & $0.3856(4)$ & $0.0762(2)$ & $0.97532(18)$ & $0.0037(4)$ \\
H1A & $0.254(5)$ & $0.019(3)$ & $0.903(2)$ & $0.004^{*}$ \\
H1B & $0.269(5)$ & $0.131(3)$ & $1.047(2)$ & $0.004^{*}$ \\
N1 & $0.5508(3)$ & $0.2442(2)$ & $0.91610(14)$ & $0.0044(4)$ \\
H1C & $0.660(5)$ & $0.305(3)$ & $0.983(2)$ & $0.007^{*}$ \\
H1D & $0.444(5)$ & $0.328(4)$ & $0.885(2)$ & $0.007^{*}$ \\
H1E & $0.654(5)$ & $0.206(3)$ & $0.845(2)$ & $0.007^{*}$ \\
\hline
\end{tabular}

Atomic displacement parameters $\left(\AA^{2}\right)$

\begin{tabular}{lllllll}
\hline & $U^{11}$ & $U^{22}$ & $U^{33}$ & $U^{12}$ & $U^{13}$ & $U^{23}$ \\
\hline C11 & $0.0057(3)$ & $0.0048(3)$ & $0.0023(3)$ & $-0.00036(11)$ & $-0.00138(18)$ & $-0.00050(11)$ \\
C1 & $0.0017(8)$ & $0.0051(9)$ & $0.0041(8)$ & $-0.0003(6)$ & $-0.0013(7)$ & $0.0001(5)$ \\
N1 & $0.0067(7)$ & $0.0032(7)$ & $0.0031(7)$ & $0.0013(6)$ & $-0.0015(6)$ & $0.0009(5)$ \\
\hline
\end{tabular}


Geometric parameters $\left(\AA,{ }^{\circ}\right)$

\begin{tabular}{llll}
\hline $\mathrm{C} 1-\mathrm{N} 1$ & $1.488(2)$ & $\mathrm{N} 1-\mathrm{H} 1 \mathrm{C}$ & $0.91(2)$ \\
$\mathrm{C} 1-\mathrm{C} 1^{\mathrm{i}}$ & $1.522(3)$ & $\mathrm{N} 1-\mathrm{H} 1 \mathrm{D}$ & $0.80(3)$ \\
$\mathrm{C} 1-\mathrm{H} 1 \mathrm{~A}$ & $0.99(2)$ & $\mathrm{N} 1-\mathrm{H} 1 \mathrm{E}$ & $0.89(2)$ \\
$\mathrm{C} 1-\mathrm{H} 1 \mathrm{~B}$ & $0.96(2)$ & & \\
& & & $108.8(13)$ \\
$\mathrm{N} 1-\mathrm{C} 1-\mathrm{C} 1^{\mathrm{i}}$ & $109.68(18)$ & $\mathrm{C} 1-\mathrm{N} 1-\mathrm{H} 1 \mathrm{C}$ & $114.8(16)$ \\
$\mathrm{N} 1-\mathrm{C} 1-\mathrm{H} 1 \mathrm{~A}$ & $107.3(12)$ & $\mathrm{C} 1-\mathrm{N} 1-\mathrm{H} 1 \mathrm{D}$ & $104(2)$ \\
$\mathrm{C} 1-\mathrm{C} 1-\mathrm{H} 1 \mathrm{~A}$ & $109.4(13)$ & $\mathrm{H} 1 \mathrm{C}-\mathrm{N} 1-\mathrm{H} 1 \mathrm{D}$ & $110.4(15)$ \\
$\mathrm{N} 1-\mathrm{C} 1-\mathrm{H} 1 \mathrm{~B}$ & $105.1(13)$ & $\mathrm{C} 1-\mathrm{N} 1-\mathrm{H} 1 \mathrm{E}$ & $116(2)$ \\
$\mathrm{C} 1-\mathrm{C} 1-\mathrm{H} 1 \mathrm{~B}$ & $112.8(13)$ & $\mathrm{H} 1 \mathrm{C}-\mathrm{N} 1-\mathrm{H} 1 \mathrm{E}$ & $102(2)$ \\
$\mathrm{H} 1 \mathrm{~A}-\mathrm{C} 1-\mathrm{H} 1 \mathrm{~B}$ & $112.3(17)$ & $\mathrm{H} 1 \mathrm{D}-\mathrm{N} 1-\mathrm{H} 1 \mathrm{E}$ & \\
\end{tabular}

Symmetry code: (i) $-x+1,-y,-z+2$.

Hydrogen-bond geometry $\left(\AA,{ }^{\circ}\right)$

\begin{tabular}{lllll}
\hline$D-\mathrm{H} \cdots A$ & $D-\mathrm{H}$ & $\mathrm{H} \cdots A$ & $D \cdots A$ & $D-\mathrm{H} \cdots A$ \\
\hline $\mathrm{N} 1-\mathrm{H} 1 E^{\cdots} \mathrm{C} 11$ & $0.89(2)$ & $2.27(2)$ & $3.1514(15)$ & $175(2)$ \\
$\mathrm{N} 1-\mathrm{H} 1 D^{\cdots} \mathrm{C} 11^{\mathrm{ii}}$ & $0.80(3)$ & $2.39(3)$ & $3.1770(15)$ & $170(2)$ \\
$\mathrm{N} 1-\mathrm{H} 1 C^{\cdots} \cdot \mathrm{C} 11^{\mathrm{iii}}$ & $0.91(2)$ & $2.29(2)$ & $3.1922(15)$ & $171(2)$ \\
\hline
\end{tabular}

Symmetry codes: (ii) $-x+1, y+1 / 2,-z+3 / 2$; (iii) $x,-y+1 / 2, z+1 / 2$. 